\title{
O INSTITUTO DE MEDIAÇÃO EMPRESARIAL, ATRAVÉS DA ÓTICA COMPARATIVA DO DIREITO NORTE AMERICANO E O DIREITO BRASILEIRO
}

\section{THE INSTITUTE OF BUSINESS MEDIATION, THROUGH THE COMPARATIVE OPTICS OF NORTH AMERICAN LAW AND \\ BRAZILIAN LAW}

\section{LUIZ EDUARDO DARIN CUNHA}

Mestrando em Direito Empresarial e Cidadania pelo Centro Universitário Curitiba. Membro do grupo de pesquisa em Direito Empresarial Societário: O excesso de intervenção do Estado x Desenvolvimento Social Econômico do Mestrado do Centro Universitário Curitiba. Membro do grupo de pesquisa em Epistemologia, Direito e Epistemologia e Sustentabilidade do Direito do Mestrado do Centro Universitário Curitiba. Membro do Grupo de pesquisa em Direito Comercial Nacional e Internacional do Mestrado do Centro Universitário Curitiba. Coach do Grupo de Competição em Negociação e Mediação Empresarial do Centro Universitário Curitiba. Possui graduação em Direito pelo Centro Universitário Curitiba. Possui Especialização em Arbitragem Internacional pela Faculdade de Direito Getúlio Vargas - FGV. Membro do grupo de pesquisa em leis internacionais de comercio privado do Centro Universitário Curitiba. Mootie. Aluno ouvinte dos programas de LL\&M do Centro Internacional de Estudos sobre Direito e Religião na Escola de direito J.Ruben Clark da Universidade de Brigham Young. Membro do Programo on Negociation (PON) da Escola de Direito de Harvard. Aluno ouvinte dos masterclasses em Arbitragem Internacional e Negociação Internacional das Escolas de Direito da Universidades de Miami e Georgetowm. É aluno ouvinte do programa sobre relações empresarias e influencias negociais da Universidade de Michigan. 


\section{Personalidade Acadêmica Homenageada:}

Raymundo Juliano Feitosa (Universidade Federal do Rio Grande do Norte - UFRN)

\section{RESUMO}

Inicialmente objetiva-se realizar uma analise do Direito Comparado Norte Americano, com o intuito de se entender como se da o surgimento da mediação empresarial no país, assim como a aplicação da mesma, e o papel dos personagem envoltos nela, com enfoque especial, ao papel do advogado empresarial. Também se almeja neste tocante, entender como 0 direito colaborativo fomentou a empregabilidade da mediação empresarial, e como este adentrou no contexto social estadunidense.

Em sequência verificar como foi realizado o processo de transição destes fundamentos que formam a mediação empresarial, em face do Direito brasileiro. Analisar também os anais do Congresso Nacional, para tentar-se entender, qual foi o contexto social presente na aprovação da Lei de Mediação, e as justificativas utilizadas pelo coro parlamentar para sustentar a promulgação da mesma.

Por fim, desvendar a formação e a atuação do profissional de advocacia em face das exigências do processo de mediação empresarial, se este possui procedimentos específicos, se a legislação vigente no Brasil trata de todos os aspectos no tocante ao papel da advocacia nestes procedimentos, se o toante as ementas das academias de Direito no país esgotam tal temática, se não, tentar retratar o que falta e por quê falta.

Em face do que é tratado por Antônio Carlos Gil em sua Obra, Métodos e técnicas de pesquisa social. É necessário afirmar, que o presente trabalho, irá se utilizar de uma metodologia que aprecia o, racionalismo dedutivo bibliográfico, vez que, as informações e linhas de linguagem e pensamentos traçadas durante a pesquisa.

Os pontos por esta pesquisa apresentada, através de sua problemática, visam, analisar teorias e pressupostos, que partem de um contexto geral, para atingir um contexto particular, que se dá através do recorte epistemológico, utilizado para se estudar e pesquisar os pontos elencados ao caso.

Do mesmo modo a vertente bibliográfica dos ramos da metodologia, se faz lucida, ao pé, em que, os estudos de direito comparado, se dão através de materiais 


\section{Personalidade Acadêmica Homenageada:}

Raymundo Juliano Feitosa (Universidade Federal do Rio Grande do Norte - UFRN)

e doutrinas já presentes no campo jurídico, incidindo em uma pesquisa por elementos clássicos das bibliografias, casos e doutrinas.

Até o presente momento, a pesquisa encontra-se em uma fase inicial, procurando estabelecer uma contextualização sólida para fundamentar o marco teórico da mesma, houveram algumas descobertas importantes.

Como o surgimento do Direito Colaborativo operado pelo Advoga NorteAmericano, Stuart Webb, que mesmo nos casos em que obtinha êxito, observava efeitos negativos em seus clientes decorrentes de um processo judicial extenso.

Assim, no intuito de evitar estes efeitos negativos, o advogado decidiu por não mais recorrer ao Poder Judiciário e sim tratar os assuntos de seus clientes diretamente entre eles, através de acordos e do alcance de consensos ${ }^{1}$.

Dentro deste contexto, buscou-se diversas práticas alternativas aos conflitos, que possuíssem celeridade e redução de custos, financeiros e emocionais. Nesta vertente, se destacou o Processo de Mediação. ${ }^{2}$

PALAVRAS-CHAVE: Negociação; Mediação; Direito Comparado; Direito Internacional; Direito Contratual.

\section{REFERÊNCIAS}

FÜRST, Olivia. Práticas Colaborativas no Direito de Família. INNOVARE. Rio de Janeiro, 2013. Disponível em: http://www.premioinnovare.com.br/praticas/praticascolaborativas-no-direito-de-familia. Acesso em 14.06.2019.

CARBONE, Michael. Mediation strategies: a lawyer's guide to successful negotiation. Mediate.com, Eugene, 2014. Disponível em: http://www.mediate.com/articles/carbone7.cfm . Acesso em 10.06.2019.

\footnotetext{
${ }^{1}$ FÜRST, Olivia. Práticas Colaborativas no Direito de Família. INNOVARE. Rio de Janeiro, 2013. Disponível em: <http://www.premioinnovare.com.br/praticas/praticas-colaborativas-no-direito-defamilia $>$. Acesso em 14.06.2019..

2 Disponível em: http://www.amorim.projuridico.com.br/pdf/ORIGEM\%20DA\%20MEDIA\%C3\%87\%C3\%830.pdf. Último Acesso em : 22/04/2019
} 